\title{
INTERACTION WITH A MACHINE TEACHER IMPROVES STUDENT LEARNING OUTCOMES AND TEACHING EFFECTIVENESS. RESULTS WITH WILEY DAILA FROM INDONESIA
}

\author{
ELENA PELZER, Ph.D. ${ }^{1}$
}

March 11, 2021

\begin{abstract}
With the increase in demand for online learning, machine teachers are becoming an important technology in higher education since they are expected to improve teaching effectiveness and student learning outcomes. However, machine teachers require an aptitude for technology and are associated with high initial costs. Thus, here we use a more basal form of a machine teacher that enhances the interaction but does not require advanced technological competency. In a survey study from two universities in Indonesia, we investigate how the machine teacher Wiley Daila affects the teaching and learning environment. The findings indicate that Daila is perceived as useful and increases perceived teaching effectiveness and student learning outcomes. The study also shows that more research is needed to better understand the nuances in interaction.
\end{abstract}

Keywords: machine teachers, Wiley Digital Solutions, higher education, learning experience, Bayesian statistic

\footnotetext{
${ }^{1}$ John Wiley \& Sons, 1 Fusionopolis Walk, \#07-01, Solaris South Tower, Singapore 138628, Singapore Email: epelzer@wiley.com
} 


\section{Interaction with a machine teacher improves student learning outcomes and teaching effectiveness. Results with Wiley Daila from Indonesia}

The growing interest in machine learning in academia and industry is also visible in higher education. Especially due to the COVID-19 global pandemic, higher-educational institutions have had to go online to a larger extent than ever before (Khaddage, Fayad, \& Moussallem, 2020). Kim, Merrill Jr., Xu, and Sellnow (2020, p. 1) predict that "the new era of education where machines become part of the educator pool is fast approaching." These 'machine teachers,' which can take the form of a physical embodied robot or be virtual and disembodied, support instructors and students by enabling them to engage in affective, cognitive, and behavioural learning.

While some studies have focused on identifying factors that influence teaching and learning effectiveness in an online environment (e.g., Al Ghamdi, Samarji, \& Watt, 2016; Kaufmann, Sellnow, \& Frisby, 2016; Sellnow-Richmond, Strawser, \& Sellnow, 2019), research on the effectiveness of machine teachers (as opposed to course management systems such as Moodle or Blackboard) is rare (for an exception see Kim et al., 2020). Thus, here we aim to understand how the use of a machine teacher affects perceived teaching effectiveness as well as student learning outcomes (SLO). Our contribution is twofold: First, while recent efforts have, for example, examined how students would perceive the idea of using a machine teacher in higher education (e.g., Kim et al., 2020), here we focus on users' perceptions after they had the opportunity to interact with the technology during the semester. Hence, our study shifts the level of examination from intentions to behaviour. Second, the use of machine teachers in developing countries is chronically under-researched. The present study addresses this concern by providing converging evidence from Indonesia. 
In what follows, we will first examine how the shift from traditional face-to-face to virtual learning environments has paved the way for machine teachers. Next, we define the classes of machine teachers, and their potential effects on teaching effectiveness and SLO. Then, we describe the present study's method, analytical approach and results. Finally, we discuss the implications of our findings for future research and practice.

\section{Interaction Technology in Education}

\section{From Face-to-Face to Online and Blended Learning}

The past decade has seen a rapid development from traditional face-to-face to online learning environments (OLEs) and blended learning environments (BLEs). Online learning, defined as any type of learning taking place on a digital device and via the internet, is expected to increase creativity, sharing, collaboration and engagement among students and instructors (Khaddage et al., 2020). Most higher-education leaders state that online education plays a key role in their long-term strategy (Allen \& Seaman, 2016). However, there is a critical debate about the value of online learning education-i.e., whether online teaching is effective, and how learning efficacy can be increased-with some scholars cautioning that students may feel disconnected or not enjoy the online learning experiences (Eom \& Arbaugh, 2011). One research area has therefore focused on communication styles in OLEs: In general, it was found that social presence and selfdisclosure are crucial in creating a sense of community among the students, in maintaining a positive teacher-student relationship, and in improving SLO (e.g., Kim, Song, \& Luo, 2016; Shea, Li, \& Pickett, 2006; Song, Kim, \& Park, 2019).

Another emerging research area looks more closely at BLEs, which combine elements from online learning with traditional in-person education (Khaddage, Lanham, \& Zhou, 2009). López- 
Pérez, Pérez-López, and Rodríguez-Ariza (2011), for example, showed that blended learning has a positive effect on exam marks and reduced dropout rates. In another study, Sellnow-Richmond et al. (2019) found that both blended and online formats require a strong integration of all the learning cycle dimensions (Bloom, 1956) in order to provide a meaningful and social learning environment. The authors concluded that the online component in both formats "need[s] to integrate opportunities for student engagement with classmates and the instructor, not just with readings, exams, and online speeches" (p. 9).

What enables such interaction among students and instructors in online and blended learning courses? We believe that machine teachers can play a role, given that they help teachers and students to engage in the learning process. Next, we walk through the characteristics of machine teachers in higher education.

\section{Interactiveness of Machine Teachers}

Machine teachers are defined as nonhuman, technological agents supporting both human teachers and students as tutors, assistants, advisors, and/or instructors. Although 'machine teacher' is an umbrella term, the technologies have in common that they help or enable the human teachers and students to engage in affective, cognitive, and behavioural learning (Kim et al., 2020). Machine teachers can vary in their degree of embodiment and physicality, ranging from physical robots such as Nadia Thalmanns Nadine, or virtual, anthropomorphic agents such as Microsoft's Clippy, to virtual chatbots or software/interface agents such as IBM's Jill Watson, and augmented reality agents such as the augmented piano tutor (Hantono, Nugroho, \& Santosa, 2016; Kim et al., 2020). Figure 1 illustrates these five clusters of machine teachers. 
Thus, machine teachers go beyond a mere course management system where educational material such as texts, videos or exams is made accessible, but which does not facilitate interaction between users. Machine teachers fill that void by integrating opportunities for interaction, either in an online, blended or face-to-face learning environment. 'Interaction' is a complex process between users and technology (van Berkel et al., 2020), which can be further broken down into three related but distinct concepts: Interactivity, interactability, and interactiveness. Interactivity is defined as an ongoing process of activity of interacting; interactability defines the technology's ability or propensities to engage with a user; and interactiveness describes the technology's propensity to enable users to engage with each other (Janlert \& Stolterman, 2016). For example, in human-machine communication, interactability plays a central role given that scholars evaluate the direct interaction between the human and the robot, whereas in human-human-robot interaction, interactiveness is key since scholars investigate how humans interact with each other in the presence of a machine (Rifinski et al., 2020). Hence, one possible key role of machine teachers is to provide interactiveness, facilitating instructor-student and/or student-student interactions. Rather than replacing instructors, machine teachers support instructors and students alike (Kim et al., 2020). The instructor's role then shifts towards overseeing the aid from the machine, monitoring student progress, and providing additional (e.g., pastoral) support (Edwards, Edwards, Spence, \& Li, 2018).

Next, we focus on how the interactiveness of machine teachers might affect teaching effectiveness and SLO.

\section{Effects on Teaching Effectiveness \& Student Learning Outcomes}


Machine teachers can help facilitate effective teaching, e.g. by increasing the consistency of the content delivered or the fairness of assessments or by standardizing teaching formats (Kim et al., 2020). Moreover, students can benefit from machine teachers since they are expected to facilitate communication, be immediately available, and support the students in their learning efforts, which can improve their SLO (Bhatnagar, 2020; Edwards et al., 2018). The benefits may differ, however, based on the specific class of machine teacher employed.

The effects on teaching effectiveness and SLO can be further explored by the Technology Acceptance Model (TAM; Davis, 1989). Initially, TAM was developed to explain to what degree people accept and adopt a variety of technologies. Recently, TAM has been employed to measure the acceptance of and intention to use machine teachers (e.g., Kim et al., 2020). The TAM framework proposes that perceived ease of use and perceived usefulness predict the rate of a technology's acceptance. 'Perceived ease of use' refers to how simple or difficult users perceive interaction with/use of the technology to be, whereas 'perceived usefulness' is the degree to which a user believes that using the specific technology enhances their capabilities (Davis, 1989). Although a meta-analysis by King and He (2006) found TAM to be a valid and robust predictive model, another meta-analysis revealed that the magnitude of the predictors varies, with perceived usefulness correlating strongly, but perceived ease of use only weakly, with acceptance (Ma \& Liu, 2004; see also Yucel \& Gulbahar, 2013).

Regarding machine teachers, TAM serves as a promising framework since it implies that the more useful the machine teacher is perceived to be, the likelier it is that the students and teacher accept the machine teacher, leading to an improvement in teaching effectiveness and SLO. Therefore, the case study is guided by the following research questions: 
RQ1: How useful do (a) students and (b) instructors perceive the machine teacher they interacted with?

RQ2: What impact does the machine teacher have on (a) the SLO and (b) teaching effectiveness?

\section{Methods}

\section{Wiley Daila as Basal Machine Teacher}

The virtual and disembodied machine teacher in this study is Wiley Daila (Digital Advanced Integrative Learning Applications; simply known as Daila). Daila is a digital end-toend content solution to facilitate interaction among students and instructors in OLEs/BLEs in higher education. It comprises three approaches which differ in their interaction degree: (1) The 'digital collection' platform enables instructors and students to highlight and make comments in a collection of digital textbooks, and collaboratively share these with each other. (2) The 'digital courseware' platform is implemented in the course management system, and comprises additional learning material such as animations or videos, but also machine-generated immediate feedback to assessments. The machine teacher then interacts with the students by, for example, giving clues to the correct answer if the students struggle with a certain question. (3) The 'integrated course' is a customized teaching and learning program which, among other features, enables instructors to randomize the selection of questions in an assessment and have them automatically graded. The three platforms are known separately as (1) Wiley E-Texts, (2) WileyPLUS, and (3) Orion, but taken together they are referred to as the Digital Solution 'Daila.' 
Daila can be considered a machine teacher because taken together the three platforms it comprises enable interaction among students and instructors, give immediate feedback to students, save time in the preparation and grading of assessments, and enable the instructor to monitor students' learning progress continuously. However, Daila consists of three virtual platforms and not of a single virtual agent. Moreover, in contrast to other machine agent teachers, Daila does not use Spoken Dialogue Systems which are scripted responses to imitate a conversation with the user (consider Edwards et al., 2018, for further details). Therefore, Daila is considered rather a basal form of machine teacher serving as an assistant to the instructor.

\section{Participants}

A total of 304 university students and 83 instructors at two large private universities in Indonesia participated in the study, which was conducted during two academic terms for each university, spanning 2017-2020. To enable comparisons between users and non-users of Daila, respondents who did not answer this question were screened out. After screening, the final sample for university students consisted of 257 participants; no instructors were excluded. For the first university, 117 students $(45.5 \%)$ and 44 instructors $(52.4 \%)$ responded between $2017-$ 2019. For the second university, 140 students (54.5\%) and 39 instructors (47.6\%) responded between 2018-2020. Since the surveys were distributed university-wide, participants represent a variety of fields.

\section{Procedure}

In total, eight surveys were distributed for the two universities during four semester terms each using an online survey tool (www.qualtrics.com). The surveys for students and instructors 
differed slightly but assessed the same measures (see below). The lead researcher contacted the universities' management, which distributed the survey links to their instructors and students. The link was sent at the end of the semester to ensure that participants had the opportunity to use Daila beforehand. Both universities had provided access to Daila for all instructors and students during the time of the study.

\section{Measures}

Use of Daila was measured by asking participants how many hours per week they spent with Daila for one module. Students' perceived usefulness of Daila $(\alpha=.873)$ was measured with six items (e.g., "Wiley Daila provides me with adequate preparation prior to class"; "Wiley Daila provides me with ease of locating material on e-learning platform"); instructor's perceived usefulness of Daila ( $\alpha=.872$ ) was measured with two items ("Wiley Daila helps me save time in class preparation"; "It is easy to integrate Wiley Daila into my faculty's learning management system"). Items were modified from TAM (Davis, 1989).

Perceived SLO $\left(\alpha_{\text {students }}=.922\right)$ and perceived teaching effectiveness $\left(\alpha_{\text {instructors }}=.962\right)$ were measured with 9 items covering aspects of self-efficacy, interaction, grades, and selfevaluation, among others (e.g., "I feel it makes a positive impact on [my / the students'] grades"; "It provides more opportunities to interact with [the lecturer / me] in the classroom), given the question "How do you feel [you / your students] have benefited from the use of Wiley Daila?" All items were measured on a 5-point Likert-type scale (ranging from $1=$ Strongly Disagree to 5 $=$ Strongly Agree). Note that a confirmatory factor analysis (CFA) yielded similar results as the reliability tests, providing stronger evidence for the dimensionality of the factors (see Figure 2).

- INSERT FIGURE 2 ABOUT HERE - 


\section{Analysis}

After aggregating the four datasets collected from the students as well as the four datasets from the instructors separately for each group, we analysed the two datasets (for students and instructors respectively) using JASP (version 0.13.1; JASP Team, 2020). We conducted classical and Bayesian $t$-tests, comparing Daila non-users ( $<1$ hour/week) with users $(>1$ hour/week). We examined Bayes factors (BFs), more specifically $\mathrm{BF}_{10}$ to quantify evidence in favour of the alternative hypothesis, as indicators for strength of evidence that users of Daila perceive it as more useful and report greater teaching effectiveness or improved learning outcomes compared to non-users. Bayes factors run from 0 to $\infty$; as a rule of thumb, a $\mathrm{BF}_{10}$ between 1 and 3, between 3 and 10, or greater than 10 constitutes weak, moderate, or strong evidence respectively in favour of the alternative hypothesis (van Doorn et al., 2019). Since the $t$ test is one-sided, we set the prior to .707 (Wagenmakers et al., 2018). Finally, a classical Student's $t$-test was run to assess the robustness of the results from the Bayesian analyses. For both analyses, case-wise deletion was preferred over listwise exclusion of cases.

\section{Results}

Instructors as well as students interacting with Daila perceived it as more useful than users who chose not to use it: The results from the Bayesian $t$-tests indicate moderately strong evidence for instructors $\left(\mathrm{BF}_{10}=8.16\right)$ and strong evidence for students $\left(\mathrm{BF}_{10}=91.53\right)$. This finding is supported by the classical $t$-test for students $(t(255)=3.51, \mathrm{p}<.001, \mathrm{D}=.52)$ and instructors $(t(80)=2.89, \mathrm{p}<.01, \mathrm{D}=.65)$. This analysis, which served largely as a realitycheck, thus conformed to expectations. 
The results also show that students who have interacted with Wiley Daila perceive an improvement in their SLO compared to non-users $\left(\mathrm{BF}_{10}=281.75\right)$. Moreover, the findings suggest that instructors who have used Daila perceive an improvement in their teaching effectiveness compared to non-users, although unlike the strong evidence from students, the result for perceived teaching effectiveness is relatively weak $\left(\mathrm{BF}_{10}=2.25\right)$. The pattern of findings, however, is again supported by the classical $t$-test for both $\operatorname{SLO}(t(255)=3.85, \mathrm{p}<$ $.001, \mathrm{D}=.57)$ and teaching effectiveness $(t(71)=1.92, \mathrm{p}<.05, \mathrm{D}=.46)$. Figure 3 and Figure 4 show the prior and posterior distribution, and visualize $\mathrm{BF}_{10}$ robustness. Notably, across a wide range of Cauchy prior widths, $\mathrm{BF}_{10}$ values appear relatively stable, indicating robustness to the exact choice of prior. Finally, all variables were tested for differences between universities and semester terms; all differences were non-significant.

\section{- INSERT FIGURE 3 AND FIGURE 4 ABOUT HERE -}

\section{Discussion}

Machine teachers are becoming increasingly important in higher education, a trend amplified by the current disruption in education from the COVID-19 global pandemic. As the literature review revealed, there is not one single type of machine teacher, but they appear in a variety of shapes and functions: For example, some machine teachers are mainly defined by their robotic tool aspect while others, such as a chatbot, are defined by the AI software using Spoken Dialogue Systems that enable them to 'talk' with users (Edwards et al., 2018). However, while AI and robot instructors are an exciting topic, some instructors may lack access to use these 
sophisticated machine teachers due to, for example, insufficient financial support, motivation, or skills.

Thus, in this study we tested a more basal form of machine teacher with a focus on enhancing interactiveness, i.e. enabling interaction among students, and between instructor and students. In this regard, Daila enabled the sharing of comments and highlights in textbooks, provided immediate feedback on learning assignments, and facilitated the randomized selection and grading of assessments. The basal machine teacher did not 'talk' to students by giving them answers to individual questions like a chatbot, but did offer pointers when students got an answer wrong in quizzes. From a practical standpoint, we believe that this basal approach to interaction is a feature rather than a bug given that Daila can be easily integrated into course management systems. Particularly when adopted in institutions in the developing world, which often lack the resources or expertise needed to deploy more sophisticated robot or AI-based machine teachers, a basic form of machine teacher has the potential to bridge this inequity.

The surveys' findings showed that students and instructors perceived Wiley Daila as useful (RQ1); more importantly, students stated that Wiley Daila improved their learning outcomes, and instructors also tended to believe that Wiley Daila improved their teaching effectiveness (RQ2). This effect was shown across two universities and over a longer time span, indicating a robust pattern. Given that the studies were conducted in Indonesia, they give a relatively rare insight into how developing countries could benefit in the future from end-to-end machine teacher solutions in higher education, suggesting that machine teachers have a potential role in improving educational equity since they provide access to information to all students regardless of their economic background. 
However, every study has its limitations and this one is no exception: Improved teaching effectiveness and SLO were not assessed objectively by, for example, course grades, but instead self-reported. Future research should consider a more holistic approach of measuring an effective teaching and learning environment. Moreover, other determinants of academic performance such as prior education, motivation, and so forth, might affect attitudes toward, and use of, machine teachers, and could be included in future research. Despite these limitations, our study has revealed how even a basal form of machine teacher-facilitated interaction improves the learning and teaching environment. Our study calls for more research in this important area, especially regarding basic and advanced forms of machine teachers.

\section{References}

Allen, I. E., \& Seaman, J. (2016). Online report card: Tacking online education in the United States. Newburyport, MA: Babson Survey Research Group.

Al Ghamdi, A., Samarji, A., \& Watt, A. (2016). Essential considerations in distance education in KSA: Teacher immediacy in a virtual teaching and learning environment. International Journal of Information and Education Technology, 6(1), 17-22.

\section{https://doi.org/10.7763/IJIET.2016.V6.651}

Bhatnagar, H. (2020). Artificial Intelligence-A New Horizon in Indian Higher Education. Journal of Learning and Teaching in Digital Age, 5(2), 30-34.

Bloom, B. S. (1956). Taxonomy of educational objectives: The classification of educational goals. New York: Makay.

Davis, F. D. (1989). Perceived usefulness, perceived ease of use and user acceptance of information technology. MIS Quarterly, 13(3), 318-340. 
Edwards, C., Edwards, A., Spence, P. R., \& Lin, X. (2018). I, teacher: using artificial intelligence (AI) and social robots in communication and instruction. Communication Education, 67(4), 473-480. https://doi.org/10.1080/03634523.2018.1502459

Eom, S. B., \& Arbaugh, J. B. (Eds.). (2011). Student satisfaction and learning outcomes in elearning: An introduction to empirical research. Hersey, PA: Information Science Reference.

Hantono, B. S., Nugroho, L. E., \& Santosa, P. I. (2016). Review of augmented reality agent in education. 2016 6th International Annual Engineering Seminar (InAES), 1-4. https://doi.org/10.1109/inaes.2016.7821924

Janlert, L.-E., \& Stolterman, E. (2016). The Meaning of Interactivity—Some Proposals for Definitions and Measures. Human-Computer Interaction, 32(3), 103-138. https://doi.org/10.1080/07370024.2016.1226139

JASP Team (2020). JASP (Version 0.13.1)[Computer software].

Kaufmann, R., Sellnow, D. D., \& Frisby, B. N. (2016). The development and validation of the online learning climate scale. Communication Education, 65(3), 307-321. https://doi.org/10.1080/03634523.2015.1101778

Khaddage, F., Lanham, E., \& Zhou, W. (2009). A Mobile Learning Model for Universities. ReBlending the Current Learning Environment. International Journal of Interactive Mobile Technologies, 3(1), 18-23. doi:10.3991/ijim.v3s1.949

Khaddage, F., Fayad, R., \& Moussallem, I. (2020, June). Online Learning and the Role of Technologies During COVID19 Pandemic "Higher Education Lebanon Case. In EdMedia+ Innovate Learning (pp. 623-630). Association for the Advancement of Computing in Education (AACE). 
Kim, J., Merrill Jr., K., Xu, K., \& Sellnow, D. D. (2020). My Teacher Is a Machine:

Understanding Students' Perceptions of AI Teaching Assistants in Online Education. International Journal of Human-Computer Interaction, 1-10.

https://doi.org/10.1080/10447318.2020.1801227

Kim, J., Song, H., \& Luo, W. (2016). Broadening the understanding of social presence: Implications and contributions to the mediated communication and online education. Computers in Human Behavior, 65, 672-679. https://doi.org/10.1016/j.chb.2016.07.009

King, W. R. \& He, J. (2006). A meta-analysis of the technology acceptance model. Information \& Management, 43, 740-755. https://doi.org/10.1016/j.im.2006.05.003

López-Pérez, M. V., Pérez-López, M. C., \& Rodríguez-Ariza, L. (2011). Blended learning in higher education: Students' perceptions and their relation to outcomes. Computers \& Education, 56(3), 818-826. https://doi.org/10.1016/j.compedu.2010.10.023

Ma, Q. \& Liu, L. (2004). The technology acceptance model: A meta-analysis of empirical findings. Journal of Organizational and End User Computing, 16(1), 59-72. https://doi.org/10.4018/joeuc.2004010104

Rifinski, D., Erel, H., Feiner, A., Hoffman, G., \& Zuckerman, O. (2020). Human-human-robot interaction: robotic object's responsive gestures improve interpersonal evaluation in human interaction. Human-Computer Interaction, 1-27. https://doi.org/10.1080/07370024.2020.1719839

Sellnow-Richmond, D., Strawser, M. G., \& Sellnow, D. D. (2019). Student perceptions of teaching effectiveness and learning achievement: A comparative examination of online and hybrid course delivery format. Communication Teacher, 34(3), 248-263. https://doi.org/10.1080/17404622.2019.1673456 
Shea, P., Sau Li, C., \& Pickett, A. (2006). A study of teaching presence and student sense of learning community in fully online and web-enhanced college courses. The Internet and Higher Education, 9(3), 175-190. https://doi.org/10.1016/j.iheduc.2006.06.005

Song, H., Kim, J., \& Park, N. (2019). I Know My Professor: Teacher Self-Disclosure in Online Education and a Mediating Role of Social Presence. International Journal of HumanComputer Interaction, 35(6), 448-455. https://doi.org/10.1080/10447318.2018.1455126

Van Berkel, N., Dennis, S., Zyphur, M., Li, J., Heathcote, A., \& Kostakos, V. (2020). Modeling interaction as a complex system. Human-Computer Interaction, 1-27. https://doi.org/10.1080/07370024.2020.1715221

van Doorn, J., van den Bergh, D., Bohm, U., Dablander, F., Derks, K., Draws, T., ... Wagenmakers, E. (2019, January 23). The JASP Guidelines for Conducting and Reporting a Bayesian Analysis. Preprint. https://doi.org/10.31234/osf.io/yqxfr

Wagenmakers, E.-J., Love, J., Marsman, M., Jamil, T., Ly, A., Verhagen, J., Selker, R., Gronau, Q. F., Dropmann, D., Boutin, B., Meerhoff, F., Knight, P., Raj, A., van Kesteren, E.-J., van Doorn, J., Šmíra, M., Epskamp, S., Etz, A., Matzke, D., ... Morey, R. D. (2018). Bayesian inference for psychology. Part II: Example applications with JASP. Psychonomic Bulletin \& Review, 25(1), 58-76. https://doi.org/10.3758/s13423-017-1323$\underline{7}$

Yucel, U. A., \& Gulbahar, Y. (2013). Technology Acceptance Model: A Review of the Prior Predictors. Ankara University, Journal of Faculty of Educational Sciences, 46(1), 89109. Retrieved from: http://dergiler.ankara.edu.tr/dergiler/40/1799/18997.pdf 


\section{Appendix}

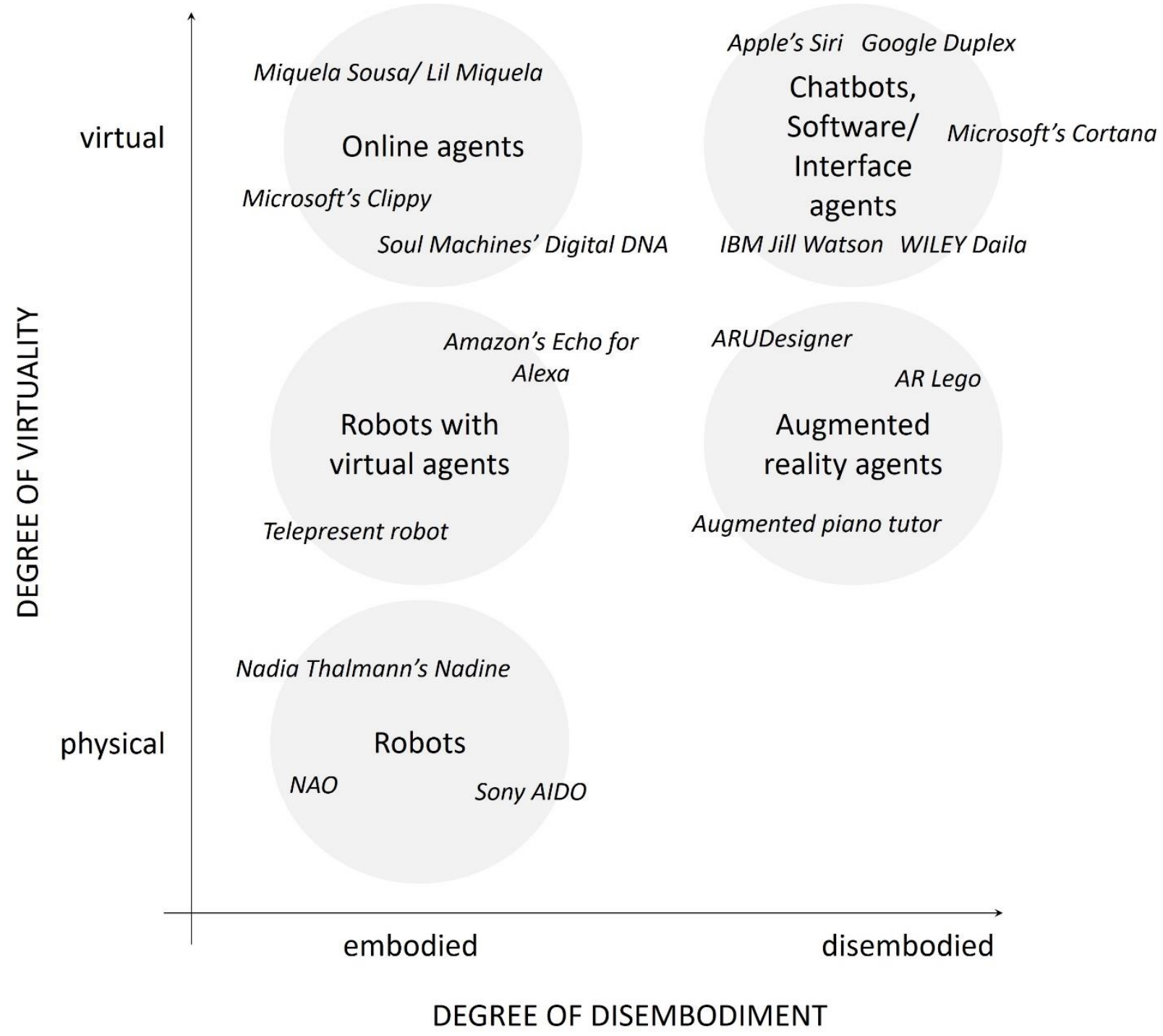

Figure 1. Classification of machine teachers and technological agents according to degree of disembodiment and virtuality. 


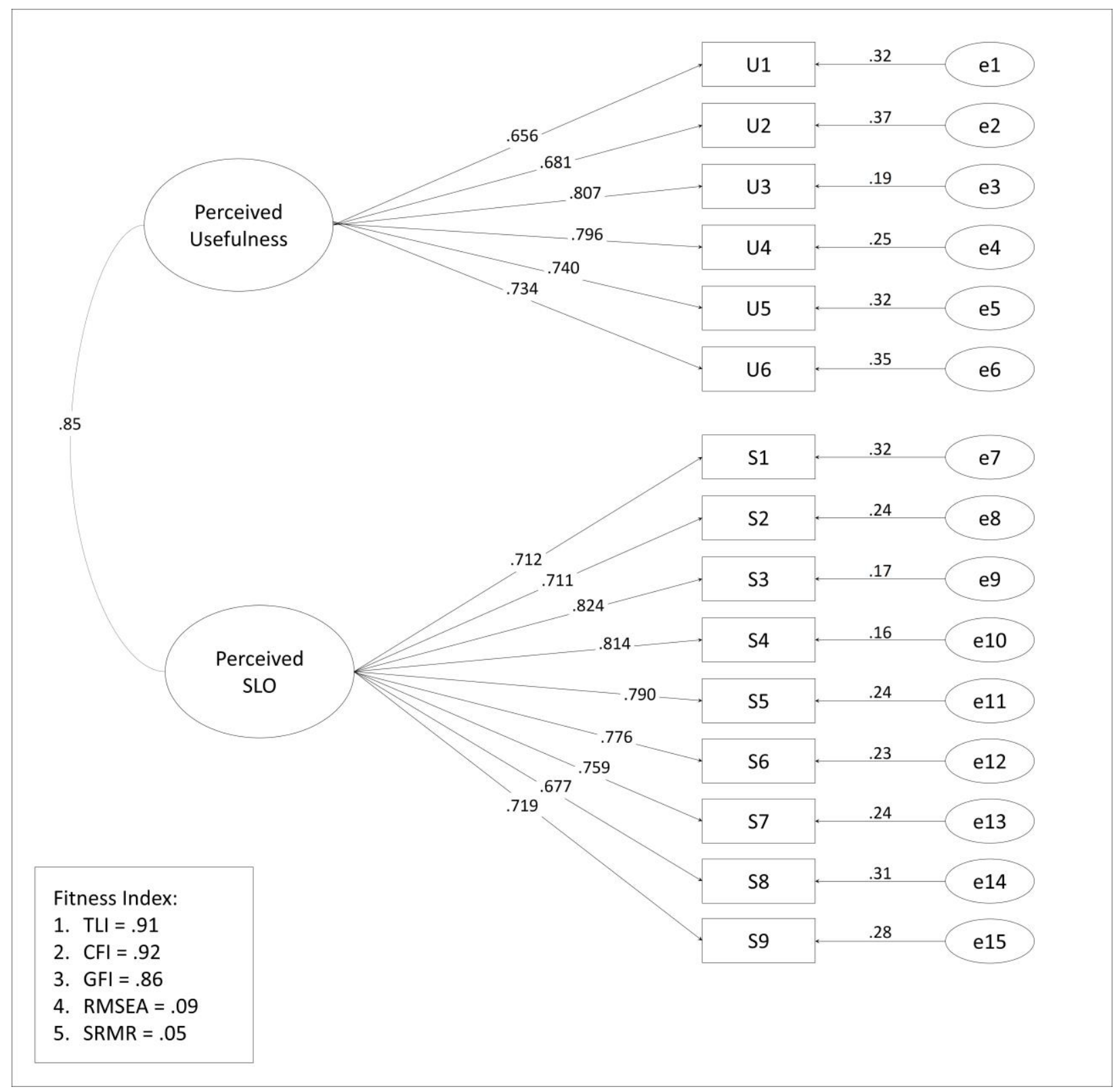

Figure 2a. CFA for students. All factor loadings are significant $(\mathrm{p}<.001)$. 


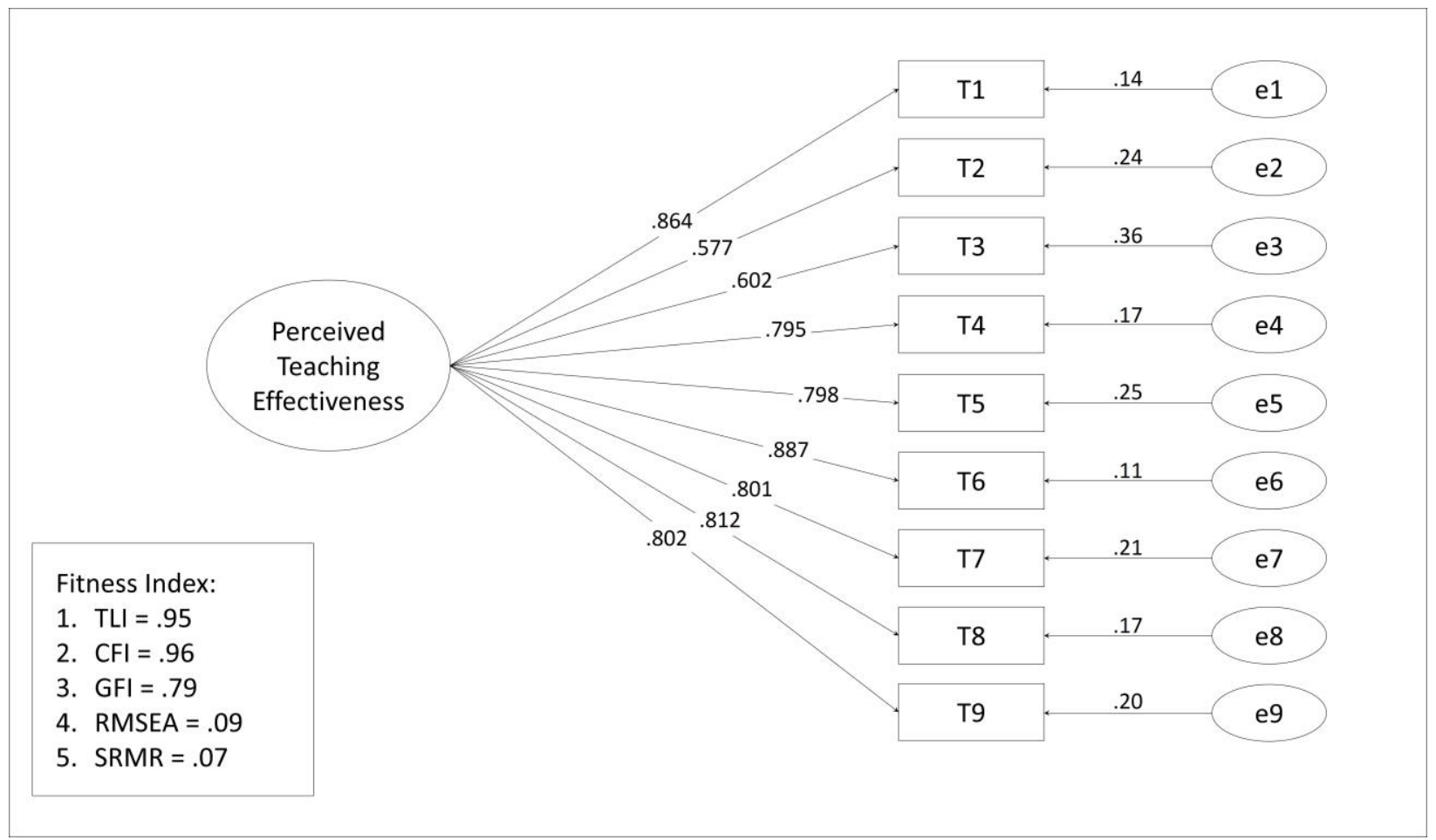

Figure 2b. CFA for instructors. All factor loadings are significant ( $\mathrm{p}<.001)$. 
$\mathbf{a}$



\section{Usefulness}

b

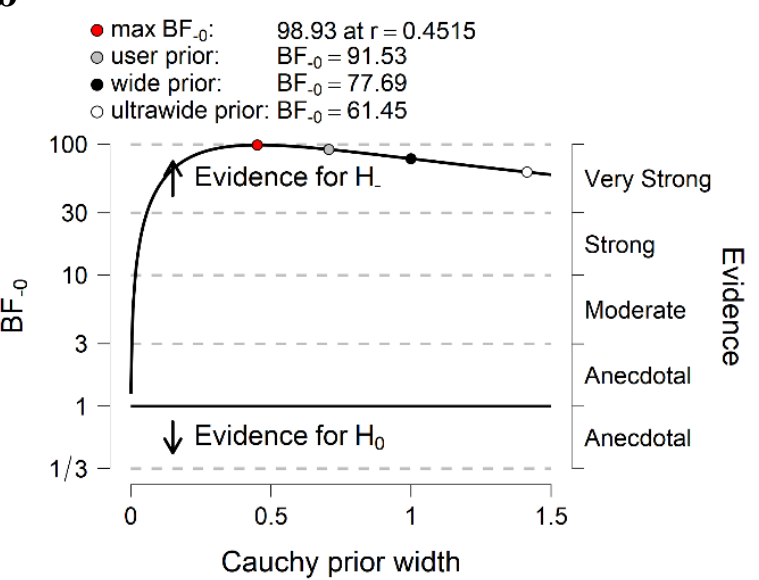

\section{Perceived Student Learning Outcomes}

c

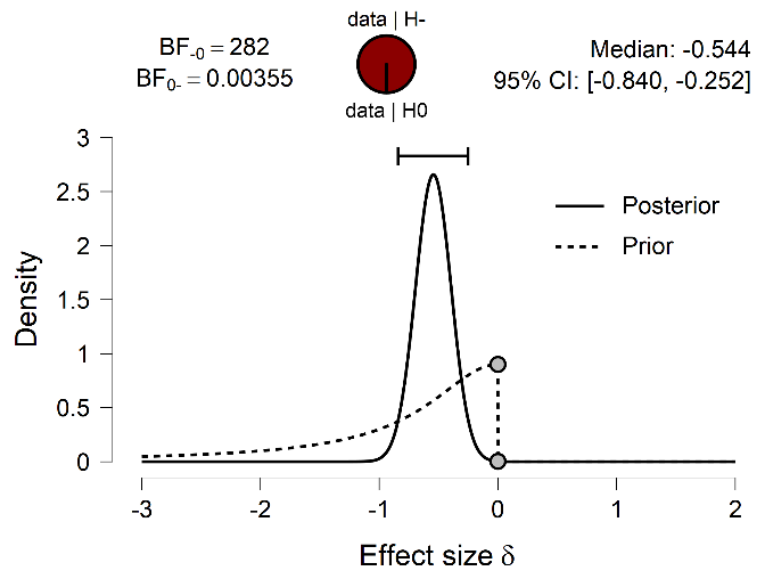

d

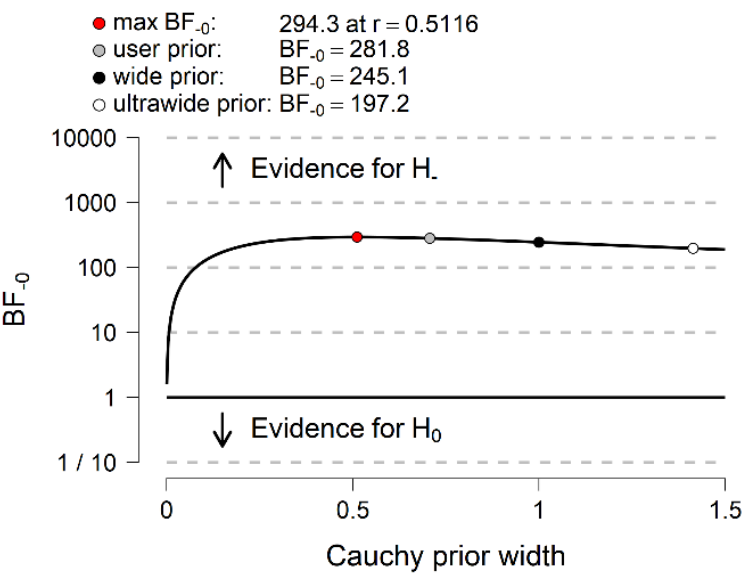

Figure 3. Bayesian $t$-tests for students. Visualizing the prior and posterior distribution for the relationship between usefulness of Wiley Daila and use of Wiley Daila (a) as well as perceived student learning outcomes and use of Wiley Daila (c). The robustness check in (b) and (d) illustrates the effects of assigning a wide range of stretched prior widths on Bayes factor values. 
a

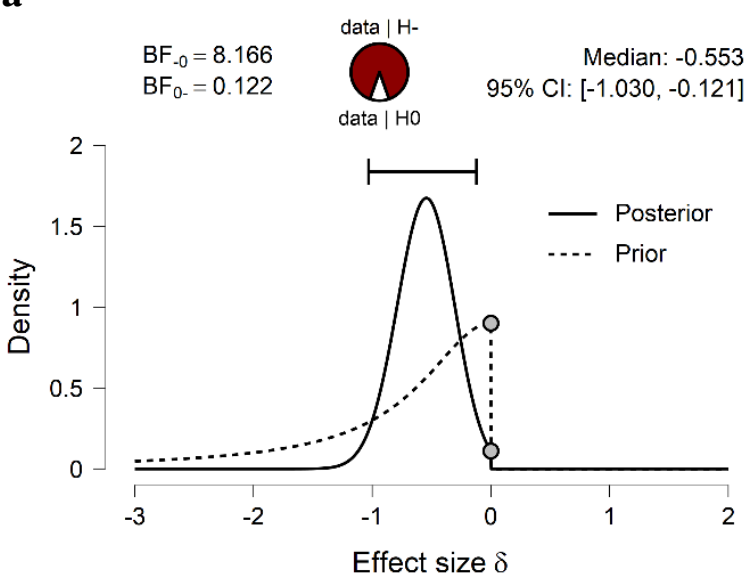

\section{Usefulness}

b

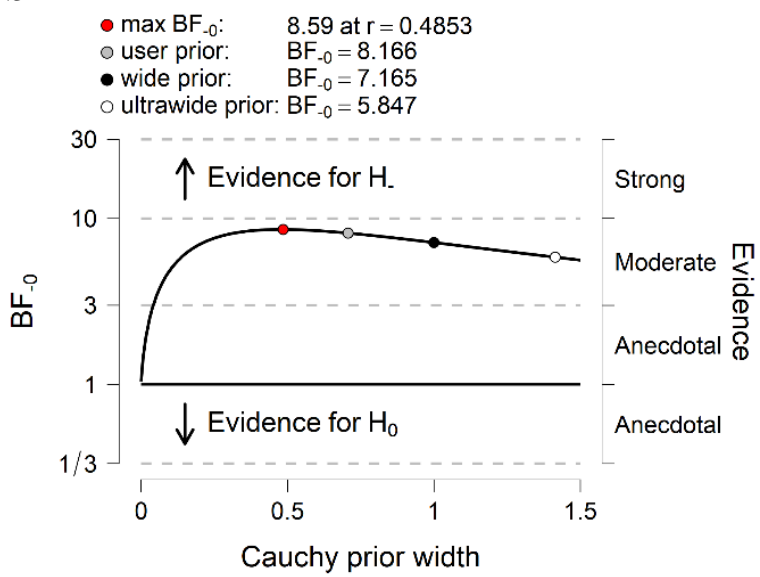

Perceived Teaching Effectiveness

c

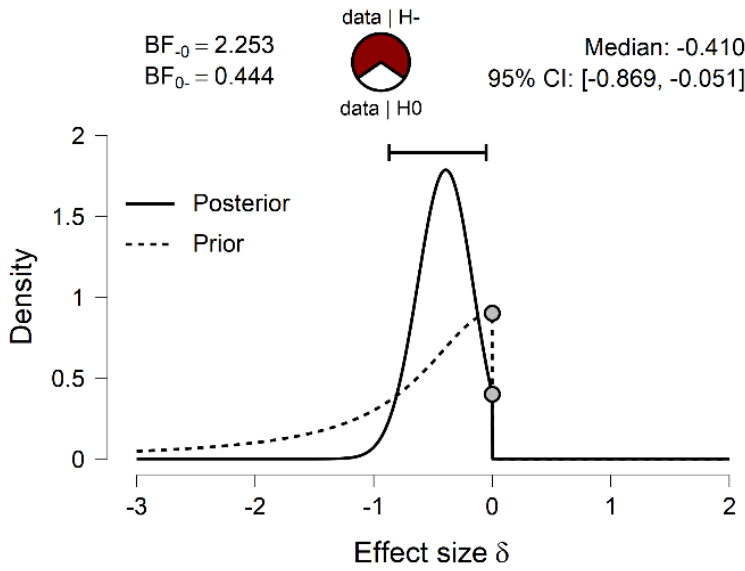

d

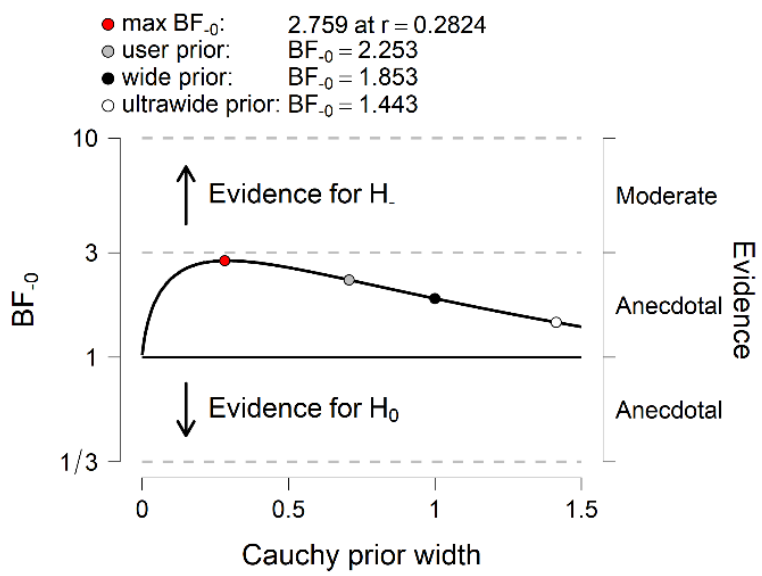

Figure 4. Bayesian $t$-tests for instructors. Visualizing the prior and posterior distribution for the relationship between usefulness of Wiley Daila and use of Wiley Daila (a) as well as perceived perceived teaching effectiveness and use of Wiley Daila (c). The robustness check in (b) and (d) illustrates the effects of assigning a wide range of stretched prior widths on Bayes factor values. 